\title{
Corrigendum: Research and
} Application of Cold Productivity Formula of Horizontal Well in the Power-Law Fluid Heavy Oil Reservoir

\section{OPEN ACCESS}

Approved by:

Frontiers Editorial Office,

Frontiers Media SA, Switzerland

*Correspondence:

Gongchang Wang

wanggch12@cnooc.com.cn

Specialty section:

This article was submitted to

Carbon Capture, Utilization and

Storage,

a section of the journal

Frontiers in Energy Research

Received: 18 November 2021

Accepted: 18 November 2021

Published: 06 December 2021

Citation:

Wang G, Liu Y and Liu Z (2021)

Corrigendum: Research and Application of Cold Productivity Formula of Horizontal Well in the Power-Law Fluid Heavy Oil Reservoir.

Front. Energy Res. 9:817439. doi: 10.3389/fenrg.2021.817439
Gongchang Wang *, Yingxian Liu and Zongbin Liu

Tianjin Branch of CNOOC Ltd., Tianjin, China

Keywords: heavy oil reservoir, power-law fluid, horizontal well, productivity, cold production

\section{A Corrigendum on}

Research and Application of Cold Productivity Formula of Horizontal Well in the Power-Law Fluid Heavy Oil Reservoir

by Gongchang W., Yingxian L., and Zongbin L. (2021). Front. Energy Res. 9:792427. doi:10.3389/fenrg. 2021.792427

In the published article, there was an error in Affiliation "1". Instead of "CNOOC Tianjin Company, Tianjin, China," it should be "Tianjin Branch of CNOOC Ltd., Tianjin, China."

The authors apologize for this error and state that this does not change the scientific conclusions of the article in any way. The original article has been updated.

Publisher's Note: All claims expressed in this article are solely those of the authors and do not necessarily represent those of their affiliated organizations, or those of the publisher, the editors and the reviewers. Any product that may be evaluated in this article, or claim that may be made by its manufacturer, is not guaranteed or endorsed by the publisher.

Copyright () 2021 Wang, Liu and Liu. This is an open-access article distributed under the terms of the Creative Commons Attribution License (CC BY). The use, distribution or reproduction in other forums is permitted, provided the original author(s) and the copyright owner(s) are credited and that the original publication in this journal is cited, in accordance with accepted academic practice. No use, distribution or reproduction is permitted which does not comply with these terms. 